\title{
FARMÁCIA
}

\section{TRATAMENTOS HOMEOPÁTICOS PARA BRONQUITE E A PERSPECTIVA FARMACÊUTICA}

\author{
DOI: http://dx.doi.org/10.31072/rcf.v9i1.548 \\ HOMEOPATHIC TREATMENTS FOR BRONCHITIS AND THE PHARMACEUTICAL \\ PERSPECTIVE
}

\begin{abstract}
Thainara Araújo de Sousa1; Alessandra Raissa de Abreu²; Josiely Paula de Souza³; Jessica Castro dos Santos ${ }^{4}$; André Tomaz Terra Júnior ${ }^{5}$.
\end{abstract}

\begin{abstract}
RESUMO: A homeopatia tem se mostrado um método eficaz contra a bronquite, além de ter a vantagem de ser mais saudável e não apresentar efeitos colaterais nos pacientes. Tem aumentado nos últimos anos a procura por medicamentos homeopáticos para o tratamento das mais diversas doenças inclusive a Bronquite, logo os quais se mostram muitos eficientes. A homeopatia trata as doenças como um desequilíbrio da energia vital, ou seja, o desequilíbrio das funções o organismo. Sendo este organismo formado por um corpo físico, alma e espírito e a energia vital a responsável pela homeostase, utilizando produtos naturais na sua composição tem sido cada vez mais a escolha das pessoas no lugar dos fármacos industrializados que apresentam muitas contraindicações e vários efeitos adversos nos pacientes. A classe farmacêutica é adepta em sua imensa maioria á alopatia, porem nos dias atuais; vem crescendo a compreensão e aceitação dos farmacêuticos para com a homeopatia.
\end{abstract}

Descritores (DeCS) ${ }^{6}$ : Tratamentos homeopáticos. Visão farmacêutica. Medicamentos homeopáticos. Bronquite.

\begin{abstract}
Homeopathy has proven to be an effective method against bronchitis, as well as having the advantage of being healthier and having no side effects in patients. In recent years there has been a growing demand for homeopathic medicines for the treatment of many diseases, including Bronchitis, which have proved to be very efficient. Homeopathy treats diseases as an imbalance of vital energy, ie, the imbalance of the body's functions. Being this body formed by a physical body, soul and spirit and vital energy responsible for homeostasis,

\footnotetext{
1 Acadêmica de Farmácia da Faculdade de Educação e Meio Ambiente - FAEMA. E-mailthataraujo_15@hotmail.com. ORCID: https://orcid.org/0000-0001-5529-0939;

2 Acadêmica de Farmácia da Faculdade de Educação e Meio Ambiente - FAEMA. E-mailalessandraraissadeabreu@gmail.com. ORCID: https://orcid.org/0000-0002-4637-7562;

3 Acadêmica de Farmácia da Faculdade de Educação e Meio Ambiente - FAEMA. E-mail: paula_josiely18@outlook.com. ORCID: https://orcid.org/0000-0001-9286-5332;

${ }^{4}$ Fisioterapeuta e Especialista em Terapia Intensiva pela Faculdade Inspirar - Curitiba / PR. Docente do curso de graduação em Fisioterapia da Faculdade de Educação e Meio Ambiente -FAEMA, Ariquemes - RO. E-mail: jessica_castro08@hotmail.com. ORCID: https://orcid.org/0000-0003-1534-8192;

${ }^{5}$ Mestre em Oncologia Clínica, Terapia Celular e Células troncos pela Faculdade de Medicina de Ribeirão Preto -FMRP/USP; Docente do curso de graduação em Farmácia da FAEMA. E-mail: andretomazfaema@gmail.com. ORCID: https://orcid.org/0000-0001-7365-5284.

6 Vide http://decs.bvs.br.
} 
using natural products in its composition has been increasingly the choice of people instead of industrialized drugs that have many contraindications and several adverse effects in the patients. The pharmaceutical class is adept in its immense majority to allopathy, but in the present day; the understanding and acceptance of pharmacists towards homeopathy has grown.

Descriptors: Homeopathic treatments. Pharmaceutical vision. Homeopathic medications. Bronchitis.

\section{INTRODUÇÃO}

Há milhares de anos as plantas são utilizadas pela humanidade para fins medicinais. É comum o uso de chás para tratamento e prevenção das mais diversas doenças no cotidiano das pessoas. Samuel Hahnemann acreditava que o enfermo necessitava ser avaliado como um todo, visando tratar não somente a doença, mas todas as questões envolvidas a ela juntamente com auxilio das plantas para se obter êxito na cura do individuo. É o que conhecemos hoje como homeopatia, que utiliza fármacos de origem vegetal, animal e mineral. (1)

A bronquite é uma doença considerada comum, porém se não tratada pode levar o doente a morte. Nota-se que cada caso é um caso e precisa ser avaliado e observado individualmente. Isso corresponde como uma das características do tratamento homeopático.

Pessoas com o mesmo tipo de bronquite podem usar medicamentos diferentes e outras com tipos de quadros distintos podem utilizar um mesmo medicamento. Funciona-se também na homeopatia, mesmo se tratando de um medicamento mais natural deve haver consciência para não ter-se o risco de uma automedicação.(2)

Contudo, este trabalho teve como objetivo, compreender as essenciais maneiras de se tratar a bronquite com homeopatia e sua colaboração para o desenvolvimento do princípio da integralidade na atenção farmacêutica, levando um conhecimento amplo acerca da homeopatia e suas propriedades.

\section{METODOLOGIA}

A presente pesquisa foi feita através de revisão bibliográfica do tipo exploratória descritiva, baseada em pesquisa em livros da biblioteca Júlio Bordignon, pertencente a Faculdade de Educação e Meio Ambiente.

Também foram pesquisados artigos em bases periódicos Google Acadêmico e Biblioteca Virtual em Saúde (BVS), utilizando as palavras-chave: Tratamentos Homeopáticos, Visão Farmacêutica, Medicamentos Homeopáticos e Bronquite. 
Foram utilizados artigos em língua portuguesa, tendo textos dispostos entre 0 período de 2012 á 2017, e outros quando se fizeram convenientes devido sua imensa importância para o trabalho.

\section{REVISÃO DE LITERATURA}

\subsection{Definição de bronquite}

A Bronquite causa inflamação respiratória, que agride geralmente os brônquios, obtendo assim um catarro que fica em várias partes do pulmão. Existem dois tipos distintos de bronquite: Bronquite Aguda e Crônica. (3)

A bronquite aguda é de pequena duração, de menor gravidade, e é obtida pelo contato com 0 frio, inalação de materiais irritantes ou até mesmo infecção. Dentre os sintomas estão estado de febre, dor no peito com frequência, dificuldade de respirar e a tosse. Já a Bronquite Crônica é de longa duração, com irritação crônica dos brônquios. Seus sintomas são tosse, algumas vezes muito frequentes principalmente de manhã, chegando a persistir cerca de dois meses consecutivos. (4)

Imunidade baixa costuma ser uma consequência de desenvolvimento de uma gripe e pode evoluir para uma bronquite crônica ou aguda, fumar pode elevar o risco de uma pessoa vir a desencadear seu quadro de bronquite, conforme a faixa etária, bebês, crianças e idosos tem mais chances de contrair a bronquite, pois seu sistema de imunidade é mais frágil e exposição a agentes irritantes e gases poluentes pode vir a fragilizar seu sistema respiratório e assim deixa-lo mais fácil para contrair a bronquite, pois a inalação dessas substâncias pode causar irritação nos pulmões. ${ }^{(5)}$

\subsection{Bronquite e seus índices etiológicos}

A bronquite tem se mostrado uma doença cada vez mais popular entre a sociedade e tem seus históricos bem vastos em postos de saúdes e hospitais a cada hora três brasileiros morrem com a Doença Pulmonar Obstrutiva Crônica (DPOC), popularmente conhecida como bronquite crônica ou enfisema pulmonar. No País acometem cerca de 40 mil mortes a cada ano, segundo o DATASUS Departamento de Informática do SUS. A bronquite é causada principalmente pelo tabagismo em suas diversas formas (cigarros, cachimbo, charuto, cigarros de Bali, narguilé, cigarro eletrônico etc), a doença leva à dificuldade de respirar e ao cansaço progressivo que dificulta a realização de atividades simples do dia a dia como andar, trocar de roupa ou tomar banho.

\subsection{Tratamentos sem sucesso com} medicamentos industrializados

Como vemos a bronquite é uma inflamação dos caminhos do ar até os 
pulmões. A doença é geralmente acompanhada de uma infecção viral respiratória, muitos médicos dão 0 diagnóstico e prescrevem alguns remédios muitos comuns e popularmente muito conhecidos como: Antibióticos, xaropes para tosse e antialérgicos, buscando assim tratar da bronquite. Os fármacos mais utilizados para o tratamento da bronquite são: Acebrofilina, Amoxilina+Clavulanato de Potássio, Bactrim e Flanax. Porém muitos destes medicamentos não mostram resultados e a bronquite persiste, sem contar que alguns não são muito apropriados para crianças, são muitas vezes tratamentos sem sucesso, pois algumas substâncias não fazem efeitos ou não são apropriadas para aquele tipo de sintoma. ${ }^{(6)}$

\subsection{Tratamentos homeopáticos}

Por muito tempo pessoas com esse tipo de infecção respiratória tem buscado diversos tratamentos, mas muitos não tem produzido o efeito desejado, diversas pessoas têm gastado em vão com tratamentos derivados de medicamentos industrializados, mas sem nenhum efeito desejado. Desde então, comenta-se muito sobre diversos tratamentos e medicamentos homeopáticos para bronquite, de baixo custo e que tem mostrado resultados positivos. ${ }^{(7)}$

\subsection{Perspectiva dos farmacêuticos sobre os medicamentos homeopáticos para cura da bronquite}

Independente de doenças e pessoas, o que se nota nos dias de hoje é a procura aos hospitais e consultórios pelo imenso aumento na ocorrência de quadros alérgicos de bronquite além de outros tipos de alergias que causam transtornos para quem vive com essa enfermidade, a cada dia são novos tratamentos e dicas sobre a doença.

Se encontram várias linhas de terapias relacionadas aos quadros de bronquite e no ver dos farmacêuticos não se tem nenhuma opinião contrária para que não se use medicamentos homeopáticos depois de recomendações médicas. Em todos os campos a prevenção e o diagnóstico precoce são as armas fundamentais para combater essa e a maioria das doenças que venham interferir na saúde do paciente. ${ }^{(8)}$

Podemos destacar que a homeopatia não busca tratar a doença e sim tratar os doentes. Isso não quer dizer que o médico ou farmacêutico homeopata não reconheça a enfermidade e não deseja que ela seja curada, mas que a doença faz parte do indivíduo, e ele deve ser tratado como um todo. A homeopatia não trata a bronquite de uma pessoa, e sim uma pessoa que tem bronquite. ${ }^{(7)}$ 
A homeopatia avalia com as mesmas maneiras qualquer tipo de especialidade médica. Cada caso é um caso e precisa ser tratado de forma individual, essa é uma propriedade do tratamento homeopático. Quem deve decidir qual método eficaz é indicado para cada caso é o médico homeopata, na alopatia há bons métodos para bronquite, mas que apresentam restrições acerca do seu tempo de uso e alguns efeitos colaterais indesejáveis importantes que obrigam a suspensão da medicação. ${ }^{(9)}$

$\mathrm{Na}$ homeopatia isso não ocorre pois não existem efeitos colaterais na mesma. No entanto há uma evidencia que na homeopatia ocorre primeiramente uma piora dos sintomas para depois melhorar, não é a intenção mas pode acontecer. $O$ fármaco homeopático provoca no organismo uma doença falsa parecida com a doença natural, porem levemente mais grave, significa que o doente pode vivenciar uma passageira agravação nos sintomas, mas que não compromete o caminho da cura ou seu estado geral. (1)

$\mathrm{Na}$ medicina homeopática há tratamento para bronquite que agem rapidamente e tratamentos que necessitam ser tomados a longo prazo. Sendo assim, pode ocorrer também na homeopatia, a melhora pode começar rapidamente, ou será necessário continuar esse tratamento por um tempo além do esperado para retornar a pessoa ao seu equilíbrio, sem ser necessário utilizar qualquer medicamento continuamente. (7)

Tanto para os farmacêuticos quanto para os médicos homeopatas o mais relevante na terapêutica para 0 paciente que tem bronquite é um acompanhamento integral desde o seu nascimento, como cuidados no ambiente em que se vive e também na forma de se alimentar-se, sempre acompanhado pelo médico homeopata ou farmacêutico homeopata evitando a auto medicação e a procura por curas milagrosas sem nenhum embasamento cientifico. ${ }^{(10)}$

\subsection{Tipos de medicamentos homeopáticos}

Com tudo isso, podemos destacar que existem centenas de medicamentos homeopáticos que são usados no tratamento da bronquite aguda e crônica. Porém cada medicamento tem sua patogênese e age sobre os sintomas diferentes, devido a isso para cada sintoma há um medicamento diferente para seu tratamento. ${ }^{(11)}$

Existem possíveis soluções para a Bronquite Aguda, dentre elas podemos citar alguns remédios homeopáticos como: Acônito (Aconitum napellus), para tosse seca e dolorosa, Drosera Rotundifolia, quando a tosse é convulsa, agravadas pelo 
calor e quando a pessoa pressiona a base do tórax, Ipecacuanha, quando á náuseas e dificuldades para respirar, Canadensis Hydrastis, quando há muco pegajoso, espesso e de cor amarelenta, Senega, quando a expectoração é dificultosa, sobre tudo em pacientes idosos. ${ }^{(12)}$

Para a Bronquite Crônica, há medicamentos homeopáticos como: Bryonia Alba, quando o catarro está congestionado no peito, dores no peito e dificuldade de inspiração, Ferrum Phosphoricum, quando há estado febril, rouquidão, queimação, tosse com muco verde e tosse seca e dolorosa, Erva- Moura, pouca tosse, secreção abundante, respiração profunda, indicado para caso de bronquite em crianças. ${ }^{(7)}$

\subsection{Porque as pessoas estão optando} por tratamentos homeopáticos?

As alterações inflamatórias do sistema respiratório, sendo bacterianas ou virais, tem por si só, as principais causas de procura aos hospitais e postos de saúde e de afastamento do trabalho. Apesar de grande parte das inflamações respiratórias terem origem viral, para as quais 0 tratamento com fármacos antimicrobianos não traz benefício algum. $A$ indicação médica de antimicrobianos é uma prática comum, tanto no atendimento de crianças como de adultos. ${ }^{(7)}$
Em consequência disso, pessoas com casos de bronquite, tem optado por tratamentos homeopáticos, pois seu custo é acessível a todos, é saudável pois seus ingredientes são naturais e seus resultados tem mostrado mais eficiência que os fármacos industriais. ${ }^{(13)}$

Segundo estudos (3) o número de pessoas com bronquite é mais frequente entre Crianças de 0-4 anos, que é cerca de $34,1 \%$ e entre adultos de $40-59$ que é cerca de $15,9 \%$. O uso de medicamentos homeopáticos utilizados por estas pessoas é cerca de $13,2 \%$, em vista de todos os medicamentos existentes, fármacos homeopáticos têm sido bastante recomendados. Encontramos muitos depoimentos em sites de medicamentos homeopáticos, relatos de pacientes que utilizam remédios homeopáticos $\mathrm{e}$ conseguiram realmente curar-se da bronquite.

Podemos citar por exemplo o caso de um senhor J.SL que teve fortes crises de bronquite quando menino e através de uma " vacina" julgou que a doença não voltaria, mas por cerca dos 30 anos, ela voltou, então procurou uma médica homeopata, Doutora Sheila Maria Franco Costa, que em seu currículo tem vários casos de pacientes com bronquite que foram tratados com medicamentos homeopáticos, logo ela prescreveu para o senhor uma dose 
determinada de Arsenicum Album, onde teve o resultado desejado. ${ }^{(14)}$

Portanto, percebe-se que alguns tratamentos com medicamentos homeopáticos têm se mostrado cada vez mais eficientes e não necessita- se ir muito longe para obter-se tratamento para a bronquite, apenas com pesquisas e busca por homeopatas de altas recomendações, pode-se conseguir alcançar um tratamento profundo, acompanhado e saudável, garantindo assim a cura da bronquite. ${ }^{(8)}$

Porém diversos casos de bronquite solucionam-se sozinhos, sem a precisão do uso de medicamentos e os sintomas somem em aproximadamente em duas semanas. Diversas vezes a bronquite não se soluciona sozinha, a melhor forma é procurar um médico que poderá lhe indicar alguns medicamentos específicos para determinados tipos de bronquite e nem sempre os sintomas serão parecido. ${ }^{(1)}$

Desde então a forma de tratamento homeopático tem como base a aplicação do princípio da lei dos semelhantes, usando medicamentos que provoquem efeitos parecidos aos sintomas da doença, tem como objetivo estimular uma reação no corpo contra seus próprios distúrbios. Ressalta-se que existem diversas formas para que 0 tratamento homeopático funcione na bronquite aguda, os sintomas geralmente desaparecem de sete a dez dias. No entanto, uma tosse seca e suspensa pode-se permanecer por vários meses, desde então o tratamento deve ser mantido até que a bronquite não apresente mais sintomas de que possa voltar brevemente. (15)

A expectativa de recuperação é muito baixa em pacientes com casos de bronquite crônica avançada, com tudo isso, a descoberta precoce da doença é de suma importância, combinados com a interrupção de hábitos que possam levar ao agravamento da bronquite, com isso melhoram gradativamente as chances de um resultado melhor no tratamento, desde que 0 paciente use a medicação corretamente indicada pelo médico ou farmacêutico homeopata e siga de forma correta com o tratamento, sendo assim pode haver uma grande expectativa de cura para a bronquite. ${ }^{(9)}$

\subsection{Algumas medidas que devem ser seguidas durante 0 tratamento homeopático}

Deve-se também prevenir a ocorrência de apresentar a bronquite como por exemplo: não fumar, tomar sempre as vacinas contra a gripe $e$ as vacinas pneumocócicas anualmente, diminuindo assim sua exposição à poluição do ar e a agentes químicos que venham causar irritação aos pulmões, lavando sempre as mãos frequentemente podendo assim 
evitar a disseminação de vírus e de outras infecções. ${ }^{(16)}$

Em casos mais graves será necessário utilizar vários tratamentos ao mesmo tempo, alternando a maneira de se tomar, de modo que se deve tomar algum medicamento sempre que houver crises e assim permitir sua melhoria. ${ }^{(15)}$ Cuidar da alimentação é de suma importância: evitando assim os amidos, a banana pode ajuda a curar, frutas e verduras não devem faltar, existem alguns chás que melhoram na cura da Bronquite e deve substituir o leite de vaca por leite de soja ou leite de aveia, pois assim como a bronquite é de origem alérgica, o principal motivo da alergia se encontra no leite de vaca, não importa como é feita a forma de comercialização e é importante evitar todos os seus derivados, bolacha, bolo, queijos. O leite de soja é mais caro, porém é mais indicado para estes casos mais graves de Bronquite. (2)

Os remédios caseiros, como xaropes e chás, podem ser úteis para complementar o tratamento da bronquite, ajudando a controlar seus sintomas, melhorando a capacidade respiratória. ${ }^{(17)}$

\section{CONSIDERAÇÕES FINAIS}

A literatura revisada mostra-se um alto índice do uso de medicamentos homeopáticos no tratamento das doenças respiratórias e principalmente no tratamento da Bronquite, destacando as que são de origem viral. A procura por tratamentos eficazes para a bronquite é muito grande e importante, tendo em vista que remédios homeopáticos são bons, mas cada medicamento apresenta um resultado diferente e seus diversos efeitos.

Este estudo revela que os fármacos de origem natural foram e ainda são um ponto relevante e com alto potencial para tratamentos seguros, tanto para bronquite como para outras doenças respiratórias, pois os medicamentos industrializados na maioria das vezes apresentam uma resposta positiva, mas volta-se os sintomas assim que o tratamento é cessado, ou seja, a doença mostra resistência sob os medicamentos, mostrando-se assim ineficaz, onde tem gerado uma grande busca por medicamentos que possam melhorar ou agir de forma paliativa sobre a doença, onde não somente medicamentos alopáticos, como também os homeopáticos tem se destacado nos últimos anos e mostrado eficiência aos pacientes que tem optado por esta forma de tratamento para a bronquite. 


\section{REFERÊNCIAS}

1. Denez KB. Percepções dos usuários da clínica pública ou privada sobre a homeopatia e acesso aos medicamentos homeopáticos. Universidade Federal De Santa Catarina UFSC. 2015 abr 17; v 1: 25 $-220$.

2. Mendonça LMO. Homeopatia no Tratamento da Bronquiolite Viral Aguda. Instituto Hahnemanniano Do Brasil. 2015 nov; v 1: 08 -26

3. Santos AC, Caes AL. A utilização de plantas medicinais na cidade de Buriti Alegre: religiosidade e cura por meio dos conhecimentos tradicionais dentro do Espiritismo Anais do Congresso de Ensino, Pesquisa e Extensão da UEG (CEPE)(ISSN 2447-8687). 2016 out 21; Vol. 3: 01-08

4. Teixeira MEH et al. "A Enfermagem No Cuidado Ao Paciente Adulto Com Bronquite." SEFIC. 2015; vol 1: 35-44

5. Ramos JU. "Bronquite infecciosa aviária: sorologia em região sem vacinação compulsória." UNESP. 2017 ago 08; vol 3: 05-17

6. Luca VD, Nicolau VR, Gonçalves TM, Marques $\mathrm{BH}$, Zanette VC, Amaral PA. Utilização de plantas medicinais no entorno do Parque Estadual da Serra Furada, Santa Catarina, Brasil: uma abordagem etnobotânica. Revista Brasileira de Biociências. 2014 mai 16; v 2: 01-05

7. Teixeira MZ. Novos medicamentos homeopáticos: Uso dos fármacos modernos segundo o princípio da similitude. Revista de Homeopatia. 2012; vol 1: 36-51

8. Silva SS. O Tratamento da rinite com o medicamento homeopático phosphorus: relato de caso. Biblioteca Virtual em Saúde. 2016; v 1: 06-47.

9 BRASIL - COMISSÃO DE SAÚDE PÚBLICA. ASSOCIAÇÃO MÉDICA HOMEOPÁTICA BRASILEIRA. A homeopatia no Sistema Único de Saúde: histórico e situação atual. Disponível em: <http://www.homeopathicum.com.br/ler>. Acesso em: 06 mai. 2017.

10. Barbosa JAA, Alves RRN. (2010). "Um chá de que?" - Animais utilizados no preparo tradicional de bebidas medicinais no agreste paraibano. Biofar, 4 (2): 1-12.

11. Pereira LCG, Zago VI. Matérias Médicas e suas Releituras: Smilax medica. Centro de Estudos de Homeopatia de Londrina - CEHL. 2016; v 1: 03 -17.

12. Rocha CO. Acupuntura no tratamento da doença pulmonar obstrutiva crônica em equinos. Instituto Homeopático Jacqueline Peker. 2012; v 1: 06-29

13. Nakaoka VY, Pereira AMO, Kashiwabara TGB. Práticas homeopáticas e sua representação social. Brazilian Journal of Surgery and Clinical Research BJSCR. 2013 nov; Vol.4,n.1: 68-70

14. Toniol R. Integralidade, holismo e responsabilidade: etnografia da promoção de terapias alternativas/complementares no SUS. In: Ferreira, Jaqueline; Fleischer, Soraya. Etnografias em serviços de saúde. Rio de Janeiro: Editora Garamond. 2014; pp. $153-178$

15. Leal KM, Ayres ACBM, Santos MG. Interagindo Plantas Medicinais E Corpo Humano No Ensino Fundamental. Rev Práxis. 2016 dez 16; v 8: 10 -20.

16. Franco RGS. "Estudo da relação dos casos de asma e bronquite em crianças menores de 5 anos e variáveis meteorológicas no município de Uberlândia-MG." UFU. 2017 mai 30; vol 2: 04-18

17. Alcantara RGL, Joaquim RHVT, Sampaio SF. Plantas medicinais: o conhecimento e uso popular. Revista de APS. 2015 dez; vol18: 01-12

18. Rodrigues KM. Terapias Integrativas e Complementares: itinerário terapêutico e espiritualidade, uma possível reflexão. Revista Contraponto. 2015; v. 2, n. 1. 
19. Azevedo AK, Klock BA, Domingues WCA. Talassoterapia: recurso terapêutico natural como forma de promoção da saúde e tratamento de patologias. UNIVERSIDADE FEDERAL DO PARANÁ. 2015; v 1: 07-20

20. Biavatti MW, Torres K. Gestão da Assistência Farmacêutica: módulo 3: unidade 5: políticas de saúde para a inserção da fitoterapia e da homeopatia no SUS. Universidade Federal de Santa Catarina. 2013 jun 06; v 1: 04-13

21.Santos EDB, Filho FJC. Panorama geral das pesquisas científicas sobre cromoterapia: Uma revisão integrativa. Cadernos De Naturologia E Terapias Complementares. 2012 jan; vol 1: 01-11

\section{Como citar (Vancouver)}

Sousa TA, Abreu AR, Souza JP, Santos JC, Terra Júnior AT. Tratamentos homeopáticos para bronquite e a perspectiva farmacêutica. Rev Cient Fac Educ e Meio Ambiente [Internet]. 2018;9(1):413-422. DOI: http://dx.doi.org/10.31072/rcf.v9i1.548 